\title{
Effects of Intravenous Immunoglobulin on the Course of Severe COVID-19: Results From a Retrospective Data Analysis of a Patient Cohort in Turkey Treated With or Without Octagam ${ }^{\circledR}$
}

Figen Esen ( $\nabla$ esenf@istanbul.edu.tr)

Istanbul University: Istanbul Universitesi

Perihan E. Özcan

Istanbul University: Istanbul Universitesi

Günseli Orhun

Istanbul University: Istanbul Universitesi

Özlem Polat

Istanbul University: Istanbul Universitesi

Illkay Anaklı

Istanbul University: Istanbul Universitesi

Gülçin Alay

Istanbul University: Istanbul Universitesi

Verda Tuna

Istanbul University: Istanbul Universitesi

Emre Çeliksoy

Istanbul University: Istanbul Universitesi

Mehmet Kilıç

Istanbul University: Istanbul Universitesi

Mutlu Mercan

Istanbul University: Istanbul Universitesi

Tufan Tukek

Istanbul University: Istanbul Universitesi

Research

Keywords: SARS-CoV 2, COVID-19, IVIG, inflammation

Posted Date: September 15th, 2020

DOI: https://doi.org/10.21203/rs.3.rs-73448/v1 
License: (c) (i) This work is licensed under a Creative Commons Attribution 4.0 International License. Read Full License 


\section{Abstract}

Background: There is some evidence from case reports and a few studies in China that critically ill COVID19 patients may benefit from treatment with intravenous immunoglobulins (IVIG). We compared clinical outcomes and biomarkers in a Turkish cohort of patients with severe COVID-19 who were treated with the institution's standard of care (SOC), either alone or in combination with IVIG.

Methods: Data from COVID-19 patients treated in two intensive care units at the University hospital of Istanbul was analyzed retrospectively. Patients received preliminary SOC according to the institution's treatment algorithm, to which Octagam $5 \%$ at $30 \mathrm{~g} /$ day for 5 days was added in one of the two wards. Both groups were compared regarding baseline characteristics, survival, and changes in inflammation markers (C-reactive protein=CRP, ferritin, procalcitonin, interleukin-6, D-dimer, leukocytes). Imbalance in baseline APACHE II scores was addressed by propensity-score-matching; otherwise Kaplan-Meier and multiple logistic regression models were used.

Results: Data from 93 patients was analyzed, 51 had received IVIG and 42 had not. About $75 \%$ of patients were male and both groups had comparable body mass index (BMI) and blood group distribution. IVIGtreated patients were younger (means $65 \mathrm{vs.} 71$ years) and had slightly lower baseline disease scores (APACHE II: 20.6 vs. 22.4 ; SOFA: 5.0 vs. 7.0 ). Overall survival (OS) was $61 \%$ in the IVIG and $38 \%$ in the control group. After controlling for imbalances at baseline, there was still a trend for better OS (OR: 2.2, $95 \% \mathrm{Cl}: 0.9-5.4, p=0.091)$ and a significantly longer median survival time with IVIG (68 vs. 18 days, $\mathrm{p}=0.014)$. IVIG significantly reduced CRP levels, but had no relevant effect on other inflammation markers.

Conclusion: Adjunct treatment with IVIG might add to the COVID-19 armamentarium, but results need to be confirmed in a randomized, controlled trial.

\section{Introduction}

The incidence of infection with severe acute respiratory syndrome coronavirus 2 (SARS-CoV 2) worldwide is still on the rise and the prevention and treatment of coronavirus disease 2019 (COVID-19) still a major challenge. Inefficiency of both prevention and treatment have an obvious impact on public health, but increasingly on the global economy as well. Although the search for break-through vaccines and new drugs is in full swing, even fast-track development may still take months, if not years. Therefore, off-label or even compassionate use of existing medications, most often in a complementary combined approach, has become legitimate practice during the pandemic.

Among those existing medications used for COVID-19 are intravenous immunoglobulins (IVIG) which are known for their anti-inflammatory effects and approved in several immune mediated disorders, including Kawasaki syndrome. Such disorders have increasingly been reported also to COVID-19 [1-5]. Recently, two marketed IVIG products were shown to react with SARS-CoV 2 antigens in vitro [6]. In line with all this, there have been case reports of COVID-19 patients who benefited from IVIG treatment [7-11]. 
A few retrospective studies on larger patient cohorts also indicated benefits in critically ill patients, specifically at high doses [12-14]. So far, this data entirely originates from studies in China. To our knowledge, we report here the first retrospective analysis of data from a European cohort of critically ill COVID-19 patients treated with IVIG in addition to local SOC. We aimed (a) to describe baseline characteristics of a cohort of critically ill COVID-19 patients admitted to intensive care units of the University Hospital of Istanbul /Turkey and (b) to determine whether the addition of high-dose IVIG to our local SOC has any measurable effect on clinical outcomes and biomarkers in these patients.

\section{Materials And Methods}

\section{Patients and study design}

From March 19 to May 26, 2020, patients with severe laboratory-confirmed COVID-19 requiring intensive care at the University Hospital of Istanbul (Turkey) were treated according to a locally developed provisional treatment algorithm, form which only highly moribund patients were exempted. Patients were treated in two wards of the same clinic. Assignment of patients to each ward thus to treatment with or without IVIG was at random and due to the availability of staff and beds. From March 27, 2020, highdose IVIG was added to SOC in only one of the two wards. The impact of this addition was analyzed retrospectively by comparing prognostic factors and outcomes in patients simultaneously enrolled in both wards. Accordingly, the current report refers to a retrospective, monocentric, open-label, observational, cohort study. The study complied with the Declaration of Helsinki and the Ethics Committee of the University Hospital approved the study (approval number: 2020/84937).

\section{Treatment}

Standard pharmaceutical treatment at our ICU comprised hydroxychloroquine (800 mg loading dose, LD; $400 \mathrm{mg} /$ day maintenance dose, MD, for 5 days), favipiravir (3200 mg LD; $1200 \mathrm{mg} /$ day MD for 5 days), azithromycin ( $500 \mathrm{mg} \mathrm{LD;} 250 \mathrm{mg} /$ day MD for 5 days), oseltamivir (150 mg/day for 5 days), tocilizumab or anakinra depending on inflammatory markers, methylprednisolone (200 mg/day), high dose vasopressors in case of septic shock, and vitamin C (6 g/day i.v. for 7 days). High-dose IVIG were added to this treatment regimen using Octagam $5 \%$ at $30 \mathrm{~g} /$ day for 5 consecutive days. Further details on the treatment criteria are specified in the University of Istanbul Directive for Follow-Up of COVID-19 Patient [15] (Supplement 1).

\section{Baseline and outcome measures}

Patient and disease characteristics documented at baseline were age, sex, blood group, Acute Physiology and Chronic Health Evaluation II (APACHE II) and Sequential Organ Failure Assessment (SOFA) scores, plasma troponin, and pro-brain natriuretic peptide (proBNP) concentrations. Plasma biomarkers of inflammation were measured at baseline and 6 days after ICU admission and treatment start. Those were C-reactive protein (CRP), ferritin, procalcitonin (PCT), interleukin (IL) 6, D-dimer, and white blood cell count (WBC). Clinical outcome measures included duration of specific treatment modalities (extracorporeal 
membrane oxygenation, vasopressors, renal replacement, cytokine adsorption, high-flow nasal cannula, and mechanical ventilation), time to start of mechanical ventilation, change in ventilation mode, ICU and hospital discharge, and overall survival.

\section{Statistical analysis}

Due to the retrospective character of the data collection all 93 patients were included in the statistical analysis. For all baseline parameters descriptive statistics were calculated by treatment group. Differences on changes from baseline between groups were assessed using non-parametric tests (Wilcoxon-Mann-Whitney). Heterogeneity in baseline disease scores was addressed by forming comparable strata using propensity-score-matching on the APACHE II score. A main effect logistic regression model was used to study the influence of the treatment on overall survival. The influence of the treatment and other baseline characteristics on survival times was evaluated using Cox regression models. Kaplan-Meier curves showing the estimate survival time distributions were computed. All statistical tests were performed two-sided at a significance level of alpha $=5 \%$.

\section{Results}

Data from 93 patients entered the analysis; 42 received SOC alone, 51 SOC along with IVIG. In both groups, about 3 out of 4 patients were male, with comparable body mass index (BMI), blood group distribution, vital signs, and respiratory status at baseline. The IVIG group was younger and had slightly lower baseline disease scores though (Table 1). There were no major differences in concomitant COVID19 treatments while distribution of concurrent diseases was different with 1.5 to 2-fold higher prevalence of diabetes and malignancies in the IVIG group and of chronic cardiac, chronic renal and cerebrovascular disease in the SOC group (Table 2). Accordingly, proBNP and troponin levels at baseline were lower in the IVIG group, i.e. 1.02 (interquartile range 0.22 to 2.54 ) vs 2.62 (0.32 to 7.48$) \mu \mathrm{g} / \mathrm{L}$ and 9.3 (21.1 to 53.0 ) vs 17.0 (56.0 to 114.0$) \mathrm{ng} / \mathrm{L}$. Otherwise, there were no significant differences in common safety laboratory parameters at baseline.

Overall ICU survival was $61 \%$ in the IVIG and $38 \%$ in the SOC group. After controlling for imbalances in the APACHE II score at baseline, there was still a trend for a better OS with IVIG (Odds Ratio: 2.2, 95\%Cl: 0.9$5.4, p=0.091$ ) and median survival times remained significantly longer (68 vs. 18 days, $p=0.014$; Figure 1 ). Beyond APACHE II, factors with significant impact on survival time were high BMI and maximum SOFA score at baseline whereas concurrent diseases were not. There were no significant differences between groups in any other time-to-event parameter (data not shown).

With regard to biomarkers, IVIG treatment significantly reduced CRP levels within 6 days whereas those remained fairly constant in the SOC-only group (Table 3). Generally, changes in remaining biomarkers of inflammation were rather small, with differences between both groups not being significant for procalcitonin, decreases in IL-6, and increases in D-dimer. Ferritin and WBC slightly decreased with and slightly increased without IVIG, resulting in significant differences between groups (Table 3). 


\section{Discussion}

This is one of the largest studies on the impact of IVIG on severe COVID-19 so far and to our knowledge the first one in a European patient cohort. Although some baseline imbalances rendered the considerable difference in the percentage of surviving patients no longer significant, the study robustly demonstrated a significantly longer survival time by IVIG and an anti-inflammatory effect, as revealed by a significant decrease in CRP levels.

These main results are in line with case reports describing recovery of deteriorating severely ill patients suffering from COVID-19 after initiation of IVIG treatment [7-11] and a small prospective open-label randomized clinical trial in the US showing in a patient subgroup with an alveolar-arterial gradient of $>200 \mathrm{~mm} \mathrm{Hg}$ at enrollment a lower rate of progression to mechanical ventilation requirement, shorter hospital and ICU stay and greater improvement in $\mathrm{PaO} 2 / \mathrm{FiO} 2$ at 7 days when treated with the combination of IVIG and SOC than with SOC alone [16]. Our study also confirmed results of two retrospective cohort studies in China [12,13], one of which demonstrated IVIG to significantly reduce 28day mortality, to decrease inflammatory response, and to improve some organ functions in a subgroup of 103 critically ill patients only. Those were defined as requiring ICU monitoring due to mechanical ventilation, shock or multiple organ failure [12]. All our patients actually met these criteria and thus our results add to the notion that critically ill COVID-19 patients may particularly benefit from IVIG. This is noteworthy, as remdesivir, the only approved COVID-19 treatment so far, created superior clinical outcomes only in hospitalized but not in critically ill patients $[17,18]$. Still, also for IVIG there might be a critical time window for use, as both Chinese studies also demonstrated superior survival outcomes in patients treated early versus late, i.e. within 7 days from hospitalization [12] and within $48 \mathrm{~h}$ from ICU admission [13].

Thus, although the results across the 3 cohort studies appear to be favorable and consistent, all three have considerable limitations: The study by Xie et al was lacking any control and comprised both severe and critically ill patients, but did not report outcomes by disease severity [13]. In the multicenter study by Shao et al, there was considerable heterogeneity in local treatment practices, particularly in the dosing of IVIG, and a considerable baseline imbalance between patient groups treated with and without IVIG (12). Although our study - already due to its single-center design - was more homogenous with regard to patient population and treatment, there was a significant imbalance in baseline disease scores between groups as well, although in contrast to the former study, the non-IVIG treated group appeared to suffer greater disease severity at baseline.

Such imbalance might be inadequately controlled for in any retrospective analysis. Therefore, in addition the growing evidence of benefits from IVIG administration in severe COVID 19 patients, a prospective, randomized, controlled trial is highly warranted.

\section{Conclusion}


Adjunct treatment with IVIG might add to the currently limited armamentarium against COVID-19. However, results need to be confirmed in a randomized, controlled trial.

\section{Abbreviations}

APACHE Acute Physiology and Chronic Health Evaluation

BMI Body mass index

COVID-19 Corona virus disease 2019

FIO2 Fraction of inspired oxygen

ICU Intensive care unit

IL Interleukin

iv Intravenous

IVIG Intravenous immunoglobulins

LD Loading dose

MD Maintenance dose

OR Odds ratio

OS Overall survival

$\mathrm{PaO2} \quad$ Arterial partial pressure of oxygen

PCT Procalcitonin

PEEP Positive end-expiratory pressure

proBNP Pro-brain natriuretic peptide

SARS-CoV Severe acute respiratory syndrome coronavirus

SOC Standard of care

SOFA Sequential Organ Failure Assessment

WBC White blood cell count

\section{Declarations}


Ethics approval and consent to participate

The study was approved by the Ethics Committee of the University Hospital of Istanbul (number: 2020/84937).

\section{Consent for publication}

Not applicable.

\section{Availability of data and materials}

The datasets used and analyzed during the current study are available from the corresponding author on reasonable request.

\section{Competing interests}

The authors declare that they have no competing interests.

\section{Funding}

The study was funded by Octapharma, including the statistical analysis and medical writing support. Octapharma did neither influence the study design, nor the collection, analysis, or interpretation of data.

\section{Authors' contributions}

FE initiated the retrospective analysis. All authors have contributed to the care of patients and the collection of data. All have read and approved the final manuscript.

\section{Acknowledgement}

We want to thank Don Dreher and Uwe Totzke for consultancy and medical writing support, funded by Octapharma.

\section{References}

1. Assini A, Benedetti L, Di Maio S, Schirinzi E, Del Sette M: New clinical manifestation of COVID-19 related Guillain-Barrè syndrome highly responsive to intravenous immunoglobulins: two Italian cases. Neurological sciences : official journal of the Italian Neurological Society and of the Italian Society of Clinical Neurophysiology 2020, 41(7):1657-1658.

2. Dalakas MC: Guillain-Barré syndrome: The first documented COVID-19-triggered autoimmune neurologic disease: More to come with myositis in the offing. Neurology $(R)$ neuroimmunology \& neuroinflammation 2020, 7(5).

3. Farzi MA, Ayromlou H, Jahanbakhsh N, Bavil PH, Janzadeh A, Shayan FK: Guillain-Barré syndrome in a patient infected with SARS-CoV-2, a case report. Journal of neuroimmunology 2020, 346:577294. 
4. Pouletty M, Borocco C, Ouldali N, Caseris M, Basmaci R, Lachaume N, Bensaid P, Pichard S, Kouider $\mathrm{H}$, Morelle $\mathrm{G}$ et al: Paediatric multisystem inflammatory syndrome temporally associated with SARSCoV-2 mimicking Kawasaki disease (Kawa-COVID-19): a multicentre cohort. Annals of the rheumatic diseases 2020, 79(8):999-1006.

5. Verdoni L, Mazza A, Gervasoni A, Martelli L, Ruggeri M, Ciuffreda M, Bonanomi E, D'Antiga L: An outbreak of severe Kawasaki-like disease at the Italian epicentre of the SARS-CoV-2 epidemic: an observational cohort study. Lancet (London, England) 2020, 395(10239):1771-1778.

6. Díez JM, Romero C, Gajardo R: Currently available intravenous immunoglobulin contains antibodies reacting against severe acute respiratory syndrome coronavirus 2 antigens. Immunotherapy 2020, 12(8):571-576.

7. Mohtadi N, Ghaysouri A, Shirazi S, Sara A, Shafiee E, Bastani E, Kokhazadeh T, Tavan H: Recovery of severely ill COVID-19 patients by intravenous immunoglobulin (IVIG) treatment: A case series. Virology 2020, 548:1-5.

8. Shi H, Zhou C, He P, Huang S, Duan Y, Wang X, Lin K, Zhou C, Zhang X, Zha Y: Successful treatment with plasma exchange followed by intravenous immunoglobulin in a critically ill patient with COVID19. International journal of antimicrobial agents 2020:105974.

9. Cao W, Liu X, Bai T, Fan H, Hong K, Song H, Han Y, Lin L, Ruan L, Li T: High-Dose Intravenous Immunoglobulin as a Therapeutic Option for Deteriorating Patients With Coronavirus Disease 2019. Open forum infectious diseases 2020, 7(3): ofaa102.

10. Lanza M, Polistina GE, Imitazione P, Annunziata A, Di Spirito V, Novella C, Fiorentino G: Successful intravenous immunoglobulin treatment in severe COVID-19 pneumonia. IDCases 2020, 21:e00794e00794.

11. Chiotos K, Bassiri H, Behrens EM, Blatz AM, Chang J, Diorio C, Fitzgerald JC, Topjian A, John ARO: Multisystem Inflammatory Syndrome in Children During the Coronavirus 2019 Pandemic: A Case Series. J Pediatric Infect Dis Soc 2020, 9(3):393-398.

12. Shao Z, Feng Y, Zhong L, Xie Q, Lei M, Liu Z, Wang C, Ji J, Liu H, Gu Z et al: Clinical efficacy of intravenous immunoglobulin therapy in critical patients with COVID-19: A multicenter retrospective cohort study. medRxiv 2020:2020.2004.2011.20061739.

13. Xie Y, Cao S, Dong H, Li Q, Chen E, Zhang W, Yang L, Fu S, Wang R: Effect of regular intravenous immunoglobulin therapy on prognosis of severe pneumonia in patients with COVID-19. The Journal of infection 2020.

14. Zhou Z, Xie S, Zhang J, Zheng F, Jiang D, Li K, Zuo Q, Yan Y, Liu J, Xie Y et al: Short-Term ModerateDose Corticosteroid Plus Immunoglobulin Effectively Reverses COVID-19 Patients Who Have Failed Low-Dose Therapy. 2020, Preprints 2020, 2020030065 (doi: 10.20944/preprints202003.0065.v1).

15. Istanbul University: Directive for Follow-Up of COVID-19 Patient. Istanbul Faculty of Medicine Coordination Board for COVID-19 2020, 10/04/2020-72186 (last update: April 10, 2020).

16. Sakoulas G, Geriak M, Kullar R, Greenwood K, Habib M, Vyas A, Ghafourian M, Dintyala VNK, Haddad F: Intravenous Immunoglobulin (IVIG) Significantly Reduces Respiratory Morbidity in COVID-19 
Pneumonia: A Prospective Randomized Trial. medRxiv 2020:2020.2007.2020.20157891.

17. Beigel JH, Tomashek KM, Dodd LE, Mehta AK, Zingman BS, Kalil AC, Hohmann E, Chu HY, Luetkemeyer A, Kline S et al: Remdesivir for the Treatment of Covid-19 - Preliminary Report. The New England journal of medicine 2020.

18. Wang Y, Zhang D, Du G, Du R, Zhao J, Jin Y, Fu S, Gao L, Cheng Z, Lu Q et al: Remdesivir in adults with severe COVID-19: a randomised, double-blind, placebo-controlled, multicentre trial. Lancet (London, England) 2020, 395(10236):1569-1578.

\section{Tables}

Table 1: Patient characteristics at ICU admission 


\begin{tabular}{|c|c|c|c|}
\hline Demographics & IVIG, $n=51$ & Control, $n=42$ & Total, $\mathrm{n}=93$ \\
\hline $\operatorname{Sex}(M / F)$ & $37 / 14(73 \% / 27 \%)$ & $31 / 11(74 \% / 26 \%)$ & $68 / 25(73 \% / 27 \%)$ \\
\hline Age (years) & $65.3 \pm 15.49(51)$ & $71.3 \pm 15.26(42)$ & $68.0 \pm 15.59(93)$ \\
\hline $\mathrm{BMI}\left(\mathrm{kg} / \mathrm{m}^{2}\right)$ & $26.3 \pm 2.95(51)$ & $26.6 \pm 2.94(42)$ & $26.4 \pm 2.94(93)$ \\
\hline \multicolumn{4}{|l|}{ Blood group } \\
\hline A & $19(43.2 \%)$ & $11(40.7 \%)$ & $30(42.3 \%)$ \\
\hline B & $5(11.4 \%)$ & $4(14.8 \%)$ & $9(12.7 \%)$ \\
\hline$A B$ & $6(13.6 \%)$ & $2(7.4 \%)$ & $8(11.3 \%)$ \\
\hline 0 & $14(31.8 \%)$ & $10(37.0 \%)$ & $24(33.8 \%)$ \\
\hline unknown & 7 & 15 & 22 \\
\hline \multicolumn{4}{|l|}{ Disease scores } \\
\hline APACHE II Score & $20.6 \pm 7.39(51)$ & $22.4 \pm 8.99(42)$ & $21.4 \pm 8.16(93)$ \\
\hline \multicolumn{4}{|l|}{ SOFA Score } \\
\hline at admission & $5.0 \pm 2.54(51)$ & $7.0 \pm 4.32(42)$ & $5.9 \pm 3.59(93)$ \\
\hline maximum & $10.1 \pm 5.67(51)$ & $10.4 \pm 5.71(42)$ & $10.2 \pm 5.66(93)$ \\
\hline \multicolumn{4}{|c|}{ Vital signs and respiratory status } \\
\hline \multicolumn{4}{|l|}{ Blood pressure $(\mathrm{mmHg})$} \\
\hline systolic & $133 \pm 30$ & $115 \pm 33$ & $124 \pm 33$ \\
\hline diastolic & $70 \pm 23(51)$ & $66 \pm 19(42)$ & $68 \pm 21(93)$ \\
\hline Body temperature $\left({ }^{\circ} \mathrm{C}\right)$ & $36.7 \pm 1.0$ & $36.7 \pm 0.8$ & $36.7 \pm 0.9(93)$ \\
\hline Heart rate (bpm) & $96 \pm 20(51)$ & $99 \pm 21(42)$ & $97 \pm 20(93)$ \\
\hline Respiratory rate (/min) & $39 \pm 8(51)$ & $37 \pm 9(42)$ & $38 \pm 8(93)$ \\
\hline $\mathrm{PaO}_{2} / \mathrm{FiO}_{2}$ ratio* & $110[83-151](51)$ & 130 [90-165] (42) & 123 [87-160] (93) \\
\hline \multicolumn{4}{|l|}{$\mathrm{FiO}_{2}(\%)^{\star}$ in patients with } \\
\hline${ }^{1}$ high-flow nasal cannula & $0.7[0.5-0.9](20)$ & $0.6[0.5-0.7](18)$ & $0.6[0.5-0.7](38)$ \\
\hline${ }^{2}$ mechanical ventilation & $0.7[0.5-0.9](30)$ & $0.8[0.6-0.9](21)$ & $0.8[0.6-0.9](51)$ \\
\hline Flow rate $^{\star}(\mathrm{L} / \mathrm{min})^{1}$ & $55[50-60](21)$ & $52.5[50-60](18)$ & $55[50-60](39)$ \\
\hline Peak Pressure $\left(\mathrm{cm} \mathrm{H}_{2} \mathrm{O}\right)^{2}$ & $29.0 \pm 5.16(30)$ & $30.0 \pm 5.24(21)$ & $29.4 \pm 5.16(51)$ \\
\hline
\end{tabular}




\begin{tabular}{|llll|}
\hline Demographics & IVIG, $\mathbf{n = 5 1}$ & Control, $\mathbf{n = 4 2}$ & Total, $\mathbf{n = 9 3}$ \\
\hline PEEP $\left(\mathrm{cm} \mathrm{H}_{2} \mathrm{O}\right)^{2}$ & $11.0 \pm 2.14(30)$ & $10.3 \pm 2.13(21)$ & $10.7 \pm 2.14(51)$ \\
\hline
\end{tabular}

APACHE II, Acute Physiology and Chronic Health Evaluation II; BMI, body mass index; FIO2, fraction of inspired oxygen; ICU, intensive care unit; $\mathrm{PaO} 2$, arterial partial pressure of oxygen; PEEP, positive endexpiratory pressure; SOFA, Sequential Organ Failure Assessment.

Values are means \pm SD (n) or $N(\%)$, except * median [interquartile range] due to non-normal distribution.

Table 2: Concurrent diseases and concomitant treatments for COVID-19

\begin{tabular}{|llll|}
\hline Concurrent diseases & IVIG, $\mathrm{n}=51$ & Control, $\mathrm{n}=42$ & Total, $\mathrm{n}=93$ \\
\hline Hypertension & $26(51.0 \%)$ & $22(52.4 \%)$ & $48(51.6 \%)$ \\
\hline Chronic cardiac disease & $16(31.4 \%)$ & $23(54.8 \%)$ & $39(41.9 \%)$ \\
\hline Diabetes & $18(35.3 \%)$ & $10(23.8 \%)$ & $28(30.1 \%)$ \\
\hline Chronic pulmonary disease & $11(21.6 \%)$ & $11(26.2 \%)$ & $22(23.7 \%)$ \\
\hline Malignancy & $9(17.7 \%)$ & $4(9.5 \%)$ & $13(14.0 \%)$ \\
\hline Chronic renal disease & $4(7.8 \%)$ & $6(14.3 \%)$ & $10(10.8 \%)$ \\
\hline Cerebrovascular disease & $2(3.9 \%)$ & $4(9.5 \%)$ & $6(6.5 \%)$ \\
\hline Concomitant treatments & & & \\
\hline Favipiravir & $19(37.3 \%)$ & $20(47.6 \%)$ & $39(41.9 \%)$ \\
\hline Hydroxychloroquine & $38(74.5 \%)$ & $37(88.1 \%)$ & $75(80.7 \%)$ \\
\hline Azithromycin & $37(72.6 \%)$ & $37(88.1 \%)$ & $74(79.6 \%)$ \\
\hline Oseltamivir & $37(72.6 \%)$ & $30(71.4 \%)$ & $67(72.0 \%)$ \\
\hline Tocilizumab & $5(9.8 \%)$ & $4(9.5 \%)$ & $9(9.7 \%)$ \\
\hline Anakinra & $3(5.9 \%)$ & $4(9.5 \%)$ & $7(7.5 \%)$ \\
\hline Acetylsalicylic acid & $21(41.2 \%)$ & $24(57.1 \%)$ & $45(48.4 \%)$ \\
\hline Low molecular weight heparins & $27(52.9 \%)$ & $28(66.7 \%)$ & $55(59.1 \%)$ \\
\hline Dipyridamole & $23(45.1 \%) *$ & $25(59.5 \%)$ & $48(51.6 \%)$ \\
\hline Corticosteroids & $2(3.9 \%)$ & $3(7.1 \%)$ & $5(5.4 \%)$ \\
\hline
\end{tabular}


* for 1 patient use is unknown.

Table 3: Change in biomarkers after 6 days from treatment start

\begin{tabular}{|c|c|c|c|c|c|c|}
\hline & & IVIG, $n=51$ & & Control, n=42 & & $\mathrm{P}_{\Delta}$ \\
\hline & & Baseline & After 6 days & Baseline & After 6 days & \\
\hline CRP & $\mathrm{mg} / \mathrm{L}$ & $139(58-203)$ & $57(15-104)$ & $107(31-189)$ & $129(14-191)$ & \\
\hline & $\Delta$ & $-71.5(-136-14$ & $n=48$ & $-0.3(-49-114)$ & $=21$ & 0.0488 \\
\hline РCT & $\mu g / L$ & $0.2(0.1-1.4)$ & $0.3(0.1-1.6)$ & $0.7(0.1-1.6)$ & $0.6(0.1-1.3)$ & \\
\hline & $\Delta$ & $-0.1(-0.3-0.3)$, & $=48$ & $0.0(-1.0-0.6)$ & & 0.5704 \\
\hline IL-6 & $\mu g / L$ & $\begin{array}{l}0.36(0.11- \\
2.96)\end{array}$ & $\begin{array}{l}0.31(0.07- \\
1.64)\end{array}$ & $\begin{array}{l}0.21(0.03- \\
1.07)\end{array}$ & $\begin{array}{l}0.25(0.02- \\
0.39)\end{array}$ & \\
\hline & $\Delta$ & $-0.06(-1.29-0$. & 5), $n=38$ & $-0.08(-0.75-0$ & 3), $n=16$ & 0.8185 \\
\hline Ferritin & $\mathrm{mg} / \mathrm{L}$ & $\begin{array}{l}0.90(0.34- \\
1.55)\end{array}$ & $\begin{array}{l}0.63(0.39- \\
0.97)\end{array}$ & $\begin{array}{l}0.85(0.28- \\
1.78)\end{array}$ & $\begin{array}{l}1.13(0.40- \\
2.74)\end{array}$ & \\
\hline & $\Delta$ & $-0.04(-0.53-0$. & $n=48$ & $0.18(-0.06-1$ & $n=22$ & 0.0302 \\
\hline $\begin{array}{l}\text { D- } \\
\text { Dimer }\end{array}$ & $\mathrm{mg} / \mathrm{L}$ & $\begin{array}{l}1.85(0.99- \\
3.09)\end{array}$ & $\begin{array}{l}2.28(1.47- \\
4.39)\end{array}$ & $\begin{array}{l}2.04(0.84 \text { - } \\
3.62)\end{array}$ & $\begin{array}{l}3.23(2.66- \\
4.25)\end{array}$ & \\
\hline & $\Delta$ & $0.52(-0.43-2.5$ & $n=48$ & $0.79(-0.91-2$ & $n=22$ & 0.7713 \\
\hline WBC & $10^{9} / \mathrm{L}$ & $\begin{array}{l}10.3(6.8- \\
14.0)\end{array}$ & $8.9(6.1-12.3)$ & $9.0(6.1-11.5)$ & $\begin{array}{l}10.9(7.3- \\
14.7)\end{array}$ & \\
\hline & $\Delta$ & $-0.8(-6.1-3.2)$, & $=46$ & $2.8(-1.2-6.3)$ & & 0.0176 \\
\hline
\end{tabular}

CRP, C-reactive protein; PCT, procalcitonin; IL-6, interleukin 6; WBC, white blood cell count. Values are medians (interquartile range); significant differences between groups in bold.

\section{Figures}




\section{Kaplan-Meier Plot}

With Number of Subjects at Risk

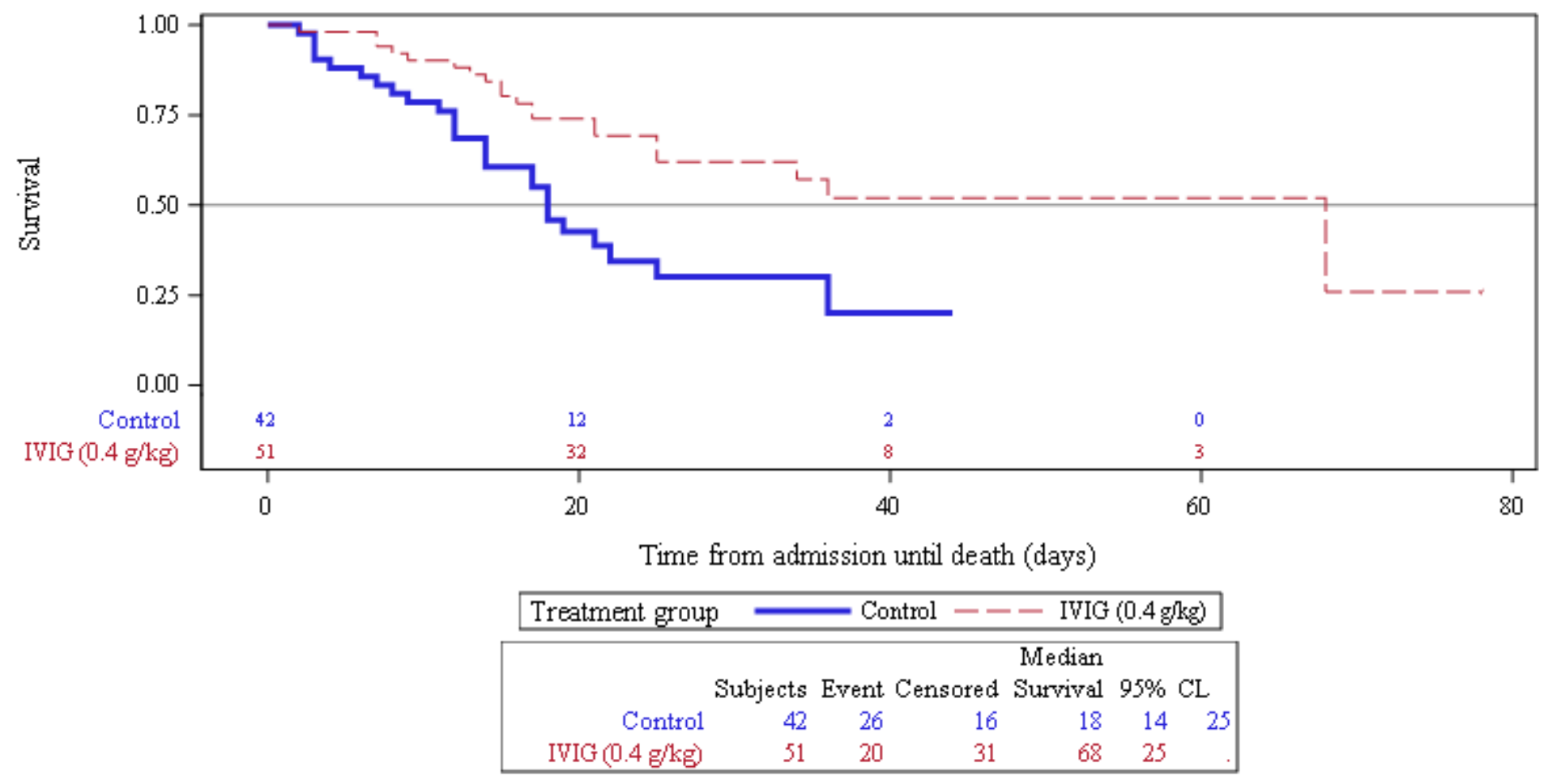

\section{Figure 1}

Survival of patients treated with SOC (control) or SOC + IVIG in addition after propensity matching. Abbreviations: SOC, standard of care; $\mathrm{CL}$, confidence limits, based on log cumulative hazard function. 